\title{
O leitor no espaço: jogo e ocupação das cidades
}

\author{
Natalia Borges Polesso*
}

Quando Kublai Khan pede a Marco Polo que conte sobre as cidades que viu, não importa quantas cidades ele tenha visto ou quão diferentes elas eram, pois essas cidades e suas paisagens sempre serão mediadas pelo ponto de vista de Marco Polo. ${ }^{1}$ É inegável que a riquíssima obra, de Ítalo Calvino, Cidades Invisíveis (1990), nos brinda com um acervo de cidades imaginárias, compondo um legítimo exercício da imaginação. No livro a experiência de leitura é fundamental, pois é no seu compartilhamento, via leitura, que elas adquirem uma dimensão espacial e referencial. É na recepção, através de um efeito de consciência englobante, presente na leitura, que as cidades vistas por Marco Polo se tornam narrativas de cidade.

Este artigo apresenta um percurso teórico e uma proposta de jogo. O percurso teórico propõe discussões sobre os conceitos de: a) mimese e verossimilhança; b) leitor e personagem; e c) mapa e paisagem, buscando sempre relações com a geografia literária e a geocrítica. Este percurso culmina na proposta de um aplicativo para celular que funcionaria por geolocalização e que considera em seu uso a ocupação dos espaços da cidade. Nesse sentido, pode-se pensar em mundo e referência de mundo, adicionando camadas à leitura e colocando o leitor numa posição mais ativa em termos de ocupação dos espaços.

\section{Mimese e verossimilhança}

Tzvetan Todorov (1972), ao revisar questões de verossimilhança, nos propõe pensá-las, desde sua definição mais ingênua, que é essa relação de verdadeiro ou falso, passando pela desconstrução da retórica na ficção até a dubiedade do conceito, quando esse se conecta com o discurso cômico. Para esse autor, a verossimilhança não está relacionada diretamente com o verdadeiro ou com o real, ela cria um efeito de realidade, produzindo relações que se estabelecem e se mantêm na escritura e na leitura de um texto, com suas próprias leis.

$\mathrm{Na}$ ficção, a verossimilhança pode se relacionar diretamente com o mundo referencial ou tangenciá-lo, por meio de outra obra de ficção, desde que esteja de

\footnotetext{
Doutora em Teoria da Literatura pela PUC-RS, Porto Alegre, RS, Brasil. E-mail: nbpoless@gmail.com.

1 O presente trabalho foi realizado com o apoio da Coordenação de Aperfeiçoamento de Pessoal de Nível Superior - Brasil (Capes) - Código de Financiamento oo1.
} 
acordo com um sistema de procedimentos aplicável. Outro ponto é a lógica do espaço, que difere em algumas culturas, e a lógica da ocupação. Por exemplo, grupos marginais ou de comunidades LGBTQ+ acabam ocupando espaços distintos ou distintamente: há uma outra lógica reivindicatória ou recriadora para que essas presenças sejam bem-sucedidas. A ocupação dos espaços oferece distintas possibilidades de interpretação do mundo e, portanto, de leitura de um texto. Não se trata de estabelecer uma verdade unívoca sobre o espaço, no qual um texto deve se agarrar para contemplar algum sentido, mas de aproximar o discurso a um referente, ou ao discurso de um referente.

Dizer a verdade é menos importante do que convencer que algo é crível. Logo, o verossímil está ligado à retórica, ao modo como a história é narrada, impactando sempre a experiência de leitura.

Quando falamos de referencialidade e intertextualidade, partimos de construções multifacetadas e nos questionamos sobre prestar contas à realidade, ou não. Por exemplo, o critério central da tese de doutorado de Polesso (2017), pesquisa desde a qual este artigo se projeta, foi a menção referencial da cidade de Porto Alegre, bem como os lugares dentro da cidade, de forma primordial e não episódica. Assim, a partir de 13 romances analisados, foram elaborados mapas virtuais de cada romance. ${ }^{2}$

Às vezes, mencionar a cidade real ou qualquer fator da realidade torna-se um tabu teórico, mesmo que os romances escolhidos projetem suas narrativas sobre o plano de uma cidade no mundo real, e mesmo que o leitor vague por esta cidade, enquanto lê uma obra que a referencia. A premissa da mimese como intertextualidade é de que, para se ler uma obra de ficção, todas as inferências partam de evidências do texto e não de fatores externos. Não importa se as coisas existam na realidade, é preciso que acreditemos na existência delas na ficção.

Contudo, é muito difícil que nossa leitura não seja contaminada pela leitura do mundo, dos discursos produzidos no mundo, por sua materialidade. As referências da cidade podem estar intimamente conectadas aos romances, e os leitores se projetam na leitura deste romance, assim como o escritor o fez no seu processo de escrita. Nesse sentido, não há como nos eximirmos da subjetividade, se negarmos isso, estaremos fadados à frustração.

\footnotetext{
2 A saber: Azurenha, Paulino; Lobo, Souza; Totta, Mário. Estrychnina. Porto Alegre: Artes e ofícios, [1897], 1998. Oliveira, Andradina de. O perdão. Porto Alegre: Livraria Americana, 1910. Machado, Dyonélio. Os ratos. Rio de Janeiro: Civilização Brasileira, 1935. Verissımo, Érico. Caminhos cruzados. Porto Alegre: Globo, 1935. MARroni, Belmonte. E as águas invadiram a metrópole. Porto Alegre: Tip. Centro, [1942?]. Martins, Cyro. Estrada nova. Porto Alegre: Editora Movimento, 1954. Scliar, Moacyr. Os voluntários. Rio de Janeiro: Expressão e Cultura, 1979. FailLACE, Tania Jamardo. Mario/Vera. Brasil 1962-1964. Rio de Janeiro: Marco Zero, 1983. Noll, João Gilberto. Rastros do verão. Porto Alegre: L\&PM, 1986. Moscovitch, Cintia. Duas iguais. Porto Alegre: LP\&M, 1998. Galera, Daniel. Mãos de cavalo. Porto Alegre: Companhia das Letras, 2006. Scotr, Paulo. Habitante irreal. Rio de Janeiro: Alfaguara, 2011. TenóRIo, Jefferson. O beijo na parede. Porto Alegre: Sulina, 2013.
} 
Para Antoine Compagnon (1998), o problema da representação, da referência ou da mimese, é uma espécie de questão tabu da crítica, e, acrescentamos: da teoria. Por isso, ele propõe repensá-lo a partir de uma pergunta que o próprio autor diz ser um simplório clichê: do que fala a literatura? Essa pergunta se divide em duas respostas: a literatura fala do mundo e a literatura fala da literatura.

Dizer que a literatura fala do mundo, das coisas materiais, primeiramente remete à ideia de arbitrariedade da língua e sua autonomia relativa com relação à realidade. Para Ferdinand de Saussure e Charles Sanders Peirce, o referente não existe fora da linguagem. A literatura fala da literatura e o referente é produzido pela significação e depende de sua interpretação. Roman Jakobson introduz as funções da linguagem e, quando propõe a função referencial, conecta a linguagem com seu contexto real, criando um modelo que aproxima a referência de uma descrição do mundo. Não há um meio de isolar a linguagem, de desespacializá-la. A linguagem não existe sem um referente. Portanto, a literatura fala do mundo e da literatura, que por sua vez fala do mundo, desde um ponto de vista construído no mundo e, ainda que subjetivo, com regras gerais, sejam elas da língua, da constituição social ou das relações interpessoais.

Para Roland Barthes (1968), a narrativa é a construção de um espetáculo enigmático, que aproxima a questão da representação à da verossimilhança, como convenção compartilhada. Assim, "a referência não é a realidade; o que chamamos de real é apenas um código. O objetivo da mimese não é produzir uma ilusão do mundo real, mas uma ilusão de discurso verdadeiro sobre o mundo real" (COMPAGNON, 1998, p. 127, tradução nossa). ${ }^{3}$

Então, o que resta do real para ser empregado na representação do espaço urbano na ficção se os limites entre o real e a ficção se tornam incertos? Todas as ciências sociais propõem uma leitura do mundo, a literatura não é diferente. Ela constitui uma via de acesso a um real não histórico (ou historicizado), não canonizado: o da narrativa. Assim, o mundo ficcional, que é também um mundo possível, corresponde a uma proposição que se desenvolve dentro e fora do mundo real. Os mundos ficcionais por serem potenciais são inevitavelmente incompletos. Dentro da narrativa, eles sempre serão representados / construídos a partir de uma perspectiva subjetiva, interpretada, advinda de uma leitura do mundo real. Além disso, as próprias escolhas narrativas são fatos delimitadores na construção de uma cidade representada.

Quando Barthes explica o effet de réel, mencionando o barômetro de Flaubert como elemento da realidade, ele quer dizer que o objeto tem a função de dar a impressão de que o texto descreve o mundo real. Complexificando o processo de mimese, o uso dos realemas, na acepção de Westphal (2007) para a construção nar-

3 No original: "la référence n'a pas de réalité; ce qu'on appelle le réel n'est qu'un code. Le but de la mimèsis n'est plus de produire une illusion du monde réel, mais une illusion de discours vrai sur le monde réel”. 
rativa, implica diretamente o potencial de interpretação dos referentes e o seu alcance. $\mathrm{O}$ efeito de real tem a função de intensificar a contiguidade entre o real e o ficcional, como se apontássemos o referente a partir do texto, diretamente no mundo. É o estar lá das coisas. Compagnon elucida que o item é como uma piscadela cúmplice para lembrar o leitor de que ele está diante de uma obra que se pretende realista. O efeito de real gera uma perspectiva interessante, além de mais ampla, porque envolve tanto a subjetividade das personagens e/ou narradores quanto a do leitor.

Paul Ricoeur (2000) entende haver uma ligação entre a mimese e o mundo. Ele a define como imitação ou representação de ações e agenciamento dos fatos. A mimese é uma imitação criadora (imitation créatrice). Esse entendimento sinaliza que de um lado há a referência ao mundo real, e do outro, a recepção dessa referência pelo leitor. Há uma criação textual do objeto que está no ofício da narrativa (sua configuração), tendo uma referência no mundo real, (sua pré-figuração), e sendo recebida pelo leitor (sua refiguração).

Representação e referencialidade são termos que se imbricam e, ao mesmo tempo, têm imensa variabilidade. ${ }^{4}$ Nossa noção se aproxima à de Ricoeur, em que a mimese é uma ficção criadora do mundo, estando inscrita no espaço e no tempo. Para elucidar melhor nosso ponto de vista, é preciso esclarecer outro elemento importante dessa equação: a experiência. A referencialidade não é uma coleção ingênua, nem os realemas são percebidos e inseridos na ficção ingenuamente. O processo de ficcionalização não se mostra isento e objetivo em nenhum momento. Dessa forma, a experiência, o modo como o mundo e seus fenômenos são interpretados e/ou vividos pelo sujeito, é parte intrínseca de nosso debate teórico.

\section{Leitor e personagem}

Na ficção, a experiência se dá por meio da personagem e/ou do narrador, sujeitos-construções ficcionais, como se esses provocassem um efeito de realidade. Revisando rapidamente algumas considerações quanto ao conceito de personagem, observa-se que a narratologia a considera uma entidade funcional, o fio condutor da narrativa. Já os imanentistas consideram a personagem um ser de papel, um ser reduzido a signos textuais, que existe apenas no texto, para que a narrativa funcione. $\mathrm{O}$ estruturalismo francês traz à discussão o effet de réel, tratando a personagem como uma elaboração do texto, ou seja, construção narrativa não autônoma. E a psicanálise as aborda como criações fictícias, produtos de um imaginário.

4 Essa variabilidade nos propõe lidar com um conceito de mimese que está longe de ser a aristotélica, em que a literatura imita o mundo e também está longe daquela em que a literatura é pura representação e que nada fora do texto é matéria da literatura. 
Essas acepções, revisadas superficialmente por não ser o foco do artigo, denotam a insuficiência do discurso narratológico, estruturalista e psicanalítico sobre a personagem. Isso levou Vincent Jouve a um questionamento interessante, deslocando a perspectiva para a recepção da personagem e se perguntando o que é a personagem para o leitor? Jouve divide a obra literária em dois polos: o artístico, texto produzido pelo autor; e o estético, a concretização da obra realizada pelo leitor. Tomando de empréstimo os termos de Wolfgang Iser (1985), Jouve entende que o foco da narrativa está mais na força perlocutória do texto, em sua capacidade de agir sobre o leitor, do que em sua força ilocutória, a intenção manifestada pelo autor.

Genette, ao discorrer sobre uma das formas de emancipação do romance moderno, afirma que a força do narrador incide diretamente sobre o leitor, instalandose na experiência de leitura:

uma das grandes formas de emancipação do romance moderno tem sido a de empurrar ao extremo, ou melhor, para o limite, esta mimese do discurso, apagando as últimas marcas da instância narrativa e dando imediatamente a palavra à personagem. Imaginemos uma narrativa iniciando (sem as aspas) com esta frase: 'É absolutamente necessário que eu me case com Albertine...' e assim até a última página, de acordo com a ordem dos pensamentos, das percepções e das ações realizados ou sofridos pelo herói. O leitor se encontra(ria) instalado, desde as primeiras linhas no pensamento da personagem principal, e é o desenrolar ininterrupto desse pensamento que, substituindo completamente a forma usual de narrativa, demonstra(ria) o que a personagem faz e o que acontece com ela (GENETTE, 1972, p. 193, tradução nossa). ${ }^{5}$

O narrador é um papel inventado e adotado pelo autor para contar a história e serve de ligação entre o leitor e as personagens. Genette entende que a personagem se instala na mente do leitor, tornando-se uma entidade completa. Jouve complementa este raciocínio, dizendo que a personagem do romance é um sujeito cognitivo, ou seja, dotado de um pensamento, de uma consciência, mas ela só se realiza na ação do leitor. Visto que um leitor virtual, suposto pela obra, é considerado um destinatário implícito dos efeitos da leitura; e, um leitor real é aquele que tem o livro em mãos, sujeito biopsicológico, a personagem é entendida como produto da interação entre ambas as instâncias, texto e leitor:

5 No original: "l'une des grandes voies d'émancipation du roman moderne aura consisté à pousser à l'extrême, ou plutôt à la limite, cette mimésis du discours, en effaçant les dernières marques de l'instance narrative et en donnant d'emblée la parole au personnage. Que l'on imagine un récit commençant (mais sans guillemets) par cette phrase : «Il faut absolument que j'épouse Albertine ... », et poursuivant ainsi, jusqu'à la dernière page, selon l'ordre des pensées, des perceptions et des actions accomplies ou subies par le héros. Le lecteur se trouve(rait) installé dès les premières lignes dans la pensée du personnage principal, et c'est le déroulement ininterrompu de cette pensée qui, se substituant complètement à la forme usuelle du récit, nous apprend(rait) ce que fait le personnage et ce qui lui arrive". 
Estudar a percepção da personagem romanesca é, portanto, determinar como e sob qual forma ela se concretiza pelo leitor [...] a identidade da personagem não pode ser concebida de outra maneira senão como o resultado de uma cooperação produtiva entre o texto e o sujeito leitor. O romance não tem, por si só, os meios de oferecer uma percepção global da personagem (Jouve, 1992, p. 27, tradução nossa). ${ }^{6}$

Para uma melhor compreensão dessa ideia de Jouve, é necessária uma leitura de Hans Robert Jauss (1978). Jauss faz uma observação fundamental para compreendermos melhor esta abordagem: o efeito se distingue da recepção. O efeito é determinado pelo texto; a recepção pelo destinatário, sendo ambos elementos constitutivos da experiência de leitura. Ou seja, a recepção da personagem está ligada parcialmente à experiência pessoal do leitor, que a compreende e lhe dá vida e, parcialmente, à representação na narrativa. A combinação desses fatores gera o efeito personagem: conjunto de relações que liga o leitor aos atores da narrativa.

A personagem é entendida como produto de uma cooperação entre o leitor e o texto. O leitor se fia nos seus conhecimentos de mundo, gerando uma interferência, e a partir dela constrói a personagem, preenchendo as lacunas e as indeterminações que proporcionam certa liberdade de interpretação para o leitor. Dessa maneira, o leitor oferece coerência ao conjunto da narrativa e atua como uma consciência englobante, que pode delinear personagens com mais propriedade, bem como modificar sua percepção sobre as personagens ao longo do texto. Jouve ainda complementa:

Na nossa perspectiva (fenomenológica), nós estamos no direito de distinguir um funcionamento de superfície da obra (que se destina ao leitor virtual/potencial) de um funcionamento profundo (que se destina ao leitor como sujeito, isto é, como suporte das reações psicológicas e pulsionais comuns a todos os indivíduos) (Jouve, 1992, p. 108, tradução nossa). ${ }^{7}$

A análise do leitor virtual permite pressupor as reações do leitor real, e uma abordagem como essa, onde o leitor é considerado parte da narrativa, ou uma consciência englobante, conduz ao entendimento da noção de personagem de maneira um pouco distinta em relação às noções mais tradicionais. Para nosso entendimento, adotamos uma perspectiva fenomenológica, que considera o nar-

\footnotetext{
No original: "Étudier la perception du personnage romanesque c'est donc déterminer comment et sous quelle forme il se concrétise pour le lecteur [...] l'identité du personnage ne peut se concevoir que comme le résultat d'une cóoperation productive entre le texte et le sujet lisant. Le roman n'a pas, à lui seul, les moyens de donner une perception globale du personnage”.

7 No original: "Dans notre perspective (phénoménologique), nous sommes donc en droit de distinguer entre un fonctionnement de surface de l'oeuvre (qui s'adresserait au lecteur virtuel) et un fonctionnement profond (qui s'adresserait au lecteur comme sujet, c'est-à-dire comme support des réactions psychologiques et pulsionnelles communes à tout individu)".
} 
rador e as personagens como entidades autônomas, bem como o leitor uma consciência englobante. ${ }^{8}$

Assim, a dimensão extratextual da personagem e do narrador é um dado indiscutível. A imagem mental do narrador e das personagens é diferente da visão ótica do leitor. Para Jouve, ela vem da competência do leitor através de dois registros fundamentais, sendo um extratextual e outro intertextual. O primeiro se dá a partir da experiência de mundo do leitor, as figuras do romance raramente são percebidas como criaturas originais, mas como mais ou menos conhecidas, implicitamente reconhecíveis em outros textos ou referências do mundo real. O segundo registro se constrói na experiência do texto, no decorrer da leitura. Assim, as personagens têm certa originalidade, unicidade e, podemos entender, certa personalidade.

É a partir das personagens e dos narradores que o leitor depreende as construções de cidade, de paisagem, de experiência de urbanidade e, finalmente, a ideia de horizonte em cada romance. O leitor nos desobriga da ingenuidade de crer que uma obra não tem impacto diferente dependendo de quem a lê. Toda e qualquer construção literária é humana e intelectual, e é a experiência, enquanto relação do sujeito com o mundo e da significação com a realidade, que nos permite observar e descrever os fenômenos.

\section{Mapa e paisagem}

Se a dimensão extratextual da personagem e do narrador está afirmada, a dimensão extratextual da paisagem é, a todo o momento, atualizada, seja com a cidade concreta atual, seja com memórias pessoais ou coletivas, história, registros e/ou outros romances que mencionem essas cidades. As personagens e/ou o narrador constroem a cidade no romance com realemas, tais como: o bonde, uma praça, a prefeitura, etc.; esses elementos estão tanto na cidade referencial como em imagens, memórias e textos que o autor colheu durante sua vida (cidade vivida, que pode ser não apenas objetivamente vivida, como pesquisada, uma cidade no plano não ficcional, parte da construção mental do autor). A intertextualidade afeta as personagens e o narrador, e intervém nas suas representações. Esse processo também se repete com o leitor, que interfere na leitura com seu conhecimento de mundo.

Collot considera a paisagem um fenômeno, o resultado da interação entre um lugar, a percepção desse lugar e sua representação, produto do encontro entre o mundo e um ponto de vista:

\footnotetext{
8 Optamos por não entrar nos domínios da psicanálise e nem da estética da recepção, sendo suficiente compartilhamos da noção de funcionalidade da leitura, do leitor e das personagens. Nossa preocupação é, evidentemente, com a instabilidade da realização da identidade das personagens e narradores, sendo ela, uma cooperação entre o texto e o leitor.
} 
O sentido de uma paisagem não é o resultado de uma análise intelectual dos elementos que a compõem, mas uma apreensão sintética das relações que os une [...]. A percepção não é a simples adição de dados sensoriais aos quais seriam conferidos por associação essa ou aquela significação, mas uma construção significante por si só (COLlot, 2011, p. 24-25, tradução nossa). ${ }^{9}$

A construção da paisagem é um ato estético e, fundamentalmente, um ato do pensamento. Collot o nomeia pensée-paysage, um espaço teórico para pensar a paisagem na narrativa e na arte. ${ }^{10}$ A paisagem emerge na obra de Collot como a imagem do mundo vivido, não sendo nem pura representação nem simples presença. A paisagem é ponto de vista, algo sempre subjetivo e ligado à experiência do sujeito, que transforma o lugar em paisagem e que torna possível a sua artialisation.

Nesse sentido, a experiência é imprescindível para a paisagem, porque ela surge da observação de uma coleção de elementos integrados, que revelam um sentido amplo quando sintetizam a relação entre eles. Essa compreensão sintética das relações que unem os elementos constituintes da paisagem, e a construção de um significante por ela mesma, é um dos aspectos da estrutura do horizonte, a qual a fenomenologia utiliza para o entendimento da experiência do sensível, e que Collot, por sua vez, engloba na sua definição de pensée-paysage: "uma coisa não é jamais percebida senão na sua relação com as outras no interior de um campo, de um horizonte externo" (Collot, 2011, p. 25, tradução nossa). ${ }^{11}$ Assim, do mesmo modo que deve se levar em conta seu horizonte interno, sua face oculta, a percepção será sempre uma perspectiva subjetiva, um ato de pensamento, em que, através de um objeto de arte (seja um livro ou uma tela), pode-se criar uma ligação com a realidade referencial e um ponto de vista particular sobre o mundo.

Posto isso, agora nos distanciamos da literatura, da narrativa, da palavra. "A distância faz com que se vejam menos os detalhes, mas faz com que se observem melhor as relações, os patterns, as formas" (MoRETti, 2008, p. 8). Para observar a paisagem é preciso certa amplitude. Nos distanciamos um pouco do texto, para poder observar a forma, no caso, os mapas das leituras dos romances. Essa leitura específica, distant reading ${ }^{12}$ não é uma leitura do texto em si, mas dos instrumen-

9 No original: "Le sens d'un paysage ne résulte pas d'une analyse intellectuelle des éléments qui le composent, mais d'une appréhension synthétique des rapports qui les unissent. [...] La perception n'est pas la simple addition de données sensorielles auxquelles serait conférée par association telle ou telle signification, mais une constructions signifiante par elle-même".

1o A fenomenologia, especialmente de Husserl e Merleau-Ponty é a base desse pensamento no que diz respeito ao conceito.

${ }^{11}$ No original "une chose n'est jamais perçue que dans son rapport à d'autres a l'intérieur d'un champ, d'un horizon externe".

${ }_{12}$ A proposta da distant reading, criada por Franco Moretti, é oposta à tradicional close reading. Ao invés de ler e analisar cuidadosamente um texto ou mesmo um conjunto de textos, a distant reading analisa computacionalmente uma quantidade maior de textos, de modo que se possa encontrar padrões ou regras implícitas, compilando esses dados. Moretti reuniu especialistas em análise de dados e tem trabalhado num software que "analisa" as obras e cria esses padrões. 
tos produzidos pela sua leitura, relacionada ao objetivo proposto: o mapa. Além de extrapolar o abstrato, essa proposta possibilita a visualização das cartografias dos romances, suas marcas e trajetos.

Necessárias para uma compreensão global do referente que propomos, seja ele a cidade, seja a narrativa da cidade, as cartografias nos colocam diante de um conjunto de informações gráficas, pensadas a partir da análise de um espaço (literário ou referencial, ou ainda ambos). Quando deixamos de olhar os mapas, não perdemos a compreensão desse todo, apenas mudamos a nossa perspectiva. Temos fragmentos do mundo. Nosso olhar se estende através do olhar das vozes narrativas e da representação criada a partir de personagens e narradores. Atravessamos décadas, o século inteiro, e ao emprestar nossa consciência a essas personagens e a esses narradores, fazemos emergir paisagens. Os narradores e as personagens nos entregam os referentes que a formam, e é a nossa leitura como ato estético, do pensamento, que a recria. A teoria propõe as lentes, a cartografia nos proporciona a visão elementar do referencial e a paisagem, como fenômeno da percepção, reconstrói a cidade.

Entendemos que a cidade é um constructo coletivo, mas a sua paisagem sempre será única e subjetiva, o que enriquece sobremaneira o modo de pensar sua geografia e sua literatura. Nesse conjunto, a experiência do leitor, como visto anteriormente, atua como uma consciência englobante, servindo como meio de compreensão também localizada num tempo-espaço.

Todavia, sendo o ponto de vista subjetivo, o romance não se "cola" no tempo simplesmente, como se fosse acessório a ele ou mesmo paralelo, ele se insere numa ideia de continuidade e virtualidade que se dá no tempo-espaço, conforme Polesso (2017, p. 212-213), ele instala um cronótopo geopoético:

isto é, na experiência do espaço narrado, e a cada romance instaura uma relação de continuidade com o tempo. A metáfora bakhtiniana confere importância a ambas as dimensões (temporal e espacial). Para nós, o cronótopo, como categoria de análise associado à geocrítica e ao pensamentopaisagem, complexifica o objeto. O entendimento de urbanização como fenômeno e de urbanidade como a produção de uma identidade e de uma mentalidade própria das cidades, nos leva a compreender nosso objeto como fragmentado. A paisagem longínqua, dominada pelo homem não se reproduz na cidade. Na cidade, o ser humano está englobado na paisagem. Ele observa e também é observado e, ao passo que quando produz uma imagem, sabe que ela está atravessada por centenas de outras imagens que ele não pode alcançar.

A dialética do visível e do invisível permanentemente permeia nossa percepção e nossa relação com os outros. A paisagem é, portanto, uma imagem mutável,

Os projetos de Moretti ligados à distant reading podem ser mais aprofundadamente estudados em seu livro Distant Reading (2013) e também no site do seu projeto na Universidade de Stanford, disponível em http://litlab.stanford.edu/. 
criada e recriada milhares de vezes pelo observador. O equilíbrio entre o que está enquadrado e o que não está reside no ponto de vista, que também é instável.

Nosso lugar epistemológico está constantemente atravessado por temporalidades e diferentes campos de relações. Sendo assim, a experiência urbana é essencial para a tentativa mínima de definir a paisagem e o gênero romance é um exercício ao mesmo tempo subjetivo e de alteridade. A personagem, inseparável do seu entorno - bem como o autor e o leitor são inseparáveis do real - tenta expressar por meio da linguagem suas relações com o mundo. Quando nós leitores encontramos um referente na realidade, nos deparamos com a dupla tarefa de expor o referente, sem destruir a ficção criada ao entorno dele. Interessa saber como ela é produzida e quais suas relações de importância e não o que a define exatamente. Se pensarmos de fato no espaço literário, na possibilidade de escritas íntimas, como define Blanchot, a relevância reside na intenção do fazer, na intenção de recriar um espaço, e não no produto final.

Foi por esse entendimento que decidimos trabalhar com as cartografias virtuais. É através da virtualidade que teoria, cartografia, literatura e paisagem se unem neste trabalho. Em minha tese de doutorado elenco elementos teóricos para explicitar nossa compreensão quanto à geografia literária, pensamento-paisagem, referencialidade, experiência e urbanidade. Alguns desses termos são discutidos em mais profundidade neste artigo, pois assim conseguimos precisar nosso entendimento quanto ao sujeito na narrativa e o processo de construção da paisagem na literatura via experiência do leitor. A seguir, propusemos cartografias das obras escolhidas (especificadas na nota de rodapé número 1) para que ficassem claramente marcados sobre um mapa os locais escolhidos pelos autores e, a partir dessas cartografias, verificarmos e aprofundarmos na história dos elementos mais mencionados e os mais relevantes para a construção da paisagem de Porto Alegre, elementos que se repetiam e que se modificavam no decorrer do tempo. A questão temporal é relevante para a paisagem, pois esta é um ato do pensamento, ou seja, não é monolítica, mas se redefine e se reconfigura no olhar de cada um, na experiência de cada um, seres no mundo e no tempo. Concretizamos os mapas das narrativas em espaços virtuais, imensos em possibilidades, porém definidos pela clareza e precisão de um satélite. Nossos mapas, como foram pensados, são impossíveis de existir em papel, pois se desdobram em narrativas transmidiáticas e hiperlinks. No princípio, apontaríamos apenas os lugares existentes na cidade referencial ou que tivessem endereço exato. Com a leitura mais detalhada dos romances e do suporte teórico, começamos a mapear os lugares propostos e depois optamos inclusive por indicar as localizações imprecisas, afinal as cartografias haviam se tornado objetos outros que se punham numa relação de continuidade com o romance. Com a cidade como referente, os romances como produção discursiva da cidade e os mapas, abrindo a possibilidade de um storytelling à parte, a chance de um retorno da literatura à cidade se potencializaria. 
O uso da plataforma My maps (Google Maps) nos permitiu uma gama limitada de ações. ${ }^{13}$ Ainda assim, foi possível criar mapas e a partir deles uma série de maneiras de interagir. Às nossas cartografias adicionamos textos, fotos, vídeos, links para outros blogs, sites, outros mapas, linhas do tempo, enfim, tudo o que pode ser acessado e que pode fazer conexão entre nosso objeto primeiro e a narrativa. A criação desses objetos multifacetados nos lança a outros caminhos que levariam ao retorno da literatura à cidade.

\section{A proposta}

O jogo implica que ao passar pela marcação virtual de, digamos, uma farmácia, na Rua dos Andradas, o leitor-jogador é avisado de que encontrou um vidro de estricnina e que este pertence a Neco Borba. A partir daí, ao jogador/leitor/andarilho são dados $\mathrm{x}$ pontos para encontrar outros itens relacionados àquela ou a outras histórias. Abaixo, podemos observar alguns frames da simulação de um aplicativo que chamamos provisoriamente de Litteraurbe.

O usuário faz o download do aplicativo ${ }^{14}$ Litteraurbe no celular para poder interagir com os mapeamentos literários. O ícone é uma caneta tinteiro vermelha sobre um mapa. No interior da caneta, há o desenho de uma placa de trânsito com um livro aberto. Toda vez que o usuário passar por um local da cidade que esteja mapeado no site, ele receberá a seguinte notificação: "Você está próximo de um Ponto Literário". Dessa forma, o usuário pode abrir o aplicativo e verificar no mapa, onde o item se encontra.

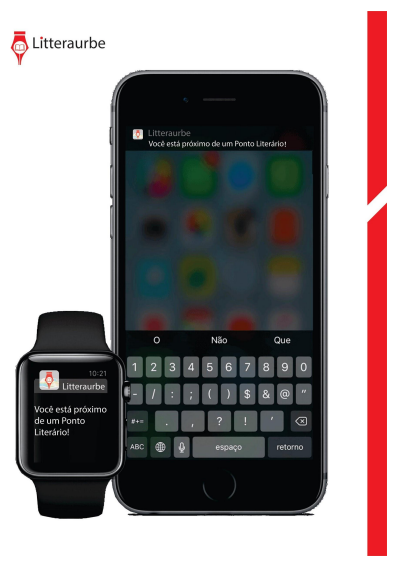

O mapa de base será como o do Google Maps, simples e de fácil compreensão, comum a diversos aplicativos. Quando o usuário abrir o mapa, poderá visualizar

13 Não é possível alterar a base de mapas e as marcações têm padrões restritos. Para um melhor aproveitamento das cartografias, seria necessário um software pago, especializado e com mais ferramentas.

${ }^{14}$ A interface do aplicativo foi desenvolvida pelo designer caxiense Arnaldo Zampieri exclusivamente para minha tese. 
todos os pontos literários próximos a ele, com uma marcação diferente para os itens que já coletou e os que ainda não foram coletados. Ao saber a localização do objeto a coletar, o usuário pode se dirigir até onde está a indicação para apanhar o item. Num projeto ideal e financiado, este item poderia ser inserido na paisagem com realidade aumentada, como acontece no jogo PokemonGo.

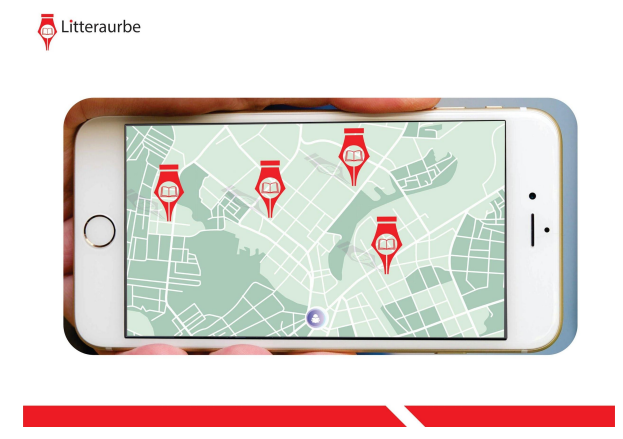

Nesse aplicativo, que funcionaria por geolocalização, o jogador/leitor, apenas pelo fato de andar pela cidade e passar por pontos mapeados, receberia informações sobre aquele lugar na literatura. Além das informações, o jogador/leitor encontraria itens importantes da literatura (presentes nos romances), realemas ressignificados. Como num quebra-cabeça, ele pode juntar as peças, e através de fragmentos do romance, entender qual o significado daquele vidro de estricnina, por exemplo. Sua recompensa pode ser uma fotografia dos autores, a foto de um original disponível em algum acervo, ou porque não, o livro físico. ${ }^{15}$

De toda forma, as cartografias produzidas mostram os rastros da literatura na cidade, nosso propósito primeiro, mas além dos rastros, elas inventam outro espaço literário. Os conjuntos de referencialidade expostos nos instigam a uma investigação mais profunda desses itens. A distant reading usado para a demarcação dos lugares num primeiro momento, para mapear, facilita e agiliza o processo, mas é uma leitura aprofundada e ramificada, composta de outros materiais e mídias o que enriquece sobremaneira as relações do sujeito com o mundo, expressas na paisagem. Ou seja, é a experiência do leitor que faz tudo acontecer. De acordo com Polesso (2017, p. 218):

Um mapa é também um discurso e, do mesmo modo que um texto, produz sentido. Nossos mapas são registros das narrativas e das memórias impregnadas nos referentes da paisagem urbana. Eles são inventários e contém suas próprias narrativas históricas e geográficas e podem ser aproveitados para inúmeros outros estudos ou projetos. Essa é uma forma de trazer a literatura de volta à cidade.

15 Para o desenvolvimento de um projeto transmidiático desse porte o trânsito nas ciências humanas digitais é fundamental, e quando escrevemos trânsito, estão implicados, além do saber, da expertise técnica, as condições materiais disponíveis. Há inúmeras maneiras de desenvolver o jogo e um sem fim de parcerias públicas e privadas que auxiliariam nesse processo, por exemplo o mapeamento de acervos. 
Quando falamos em retorno à cidade, nos interessa o leitor e a interação com o espaço. Não nos preocupa o fato de que a cartografia anule a noção de horizonte e que, portanto, não seja um elemento contido na paisagem. Justamente, por se tratar de um ponto de vista diferente e, de algum modo, uma tentativa de totalização, como Khublai quando folheia seu atlas, as cartografias ajudam a organizar os elementos paisagísticos contidos no nosso tempo-espaço. Num primeiro momento, nossas cartografias nos auxiliaram na constituição das categorias do estudo. Mapeando o romance que se passa em determinada cidade, é possível encontrar elementos mais mencionados, intrínsecos à formação concreta e intelectual daquela cidade. Esses elementos contabilizados são estabelecidos como itens da paisagem, uma tentativa de consolidar um atlas literário que estabelecerá uma relação afetiva com o leitor.

Dessa forma, a paisagem aqui se propõe como uma construção intelectual, elemento multifacetado, capaz de fazer emergir o sentido da experiência de leitor e ser urbano. Essa dupla interação com o espaço, a produção e a compreensão de sentido, somada aos fatores antagônicos da constituição da cidade, sua construção e sua degradação simultâneas, lança o sujeito sempre a uma complexa tarefa: produzir algum sentido.

Na literatura, esse sentido é produzido pelos narradores e pelas personagens e ainda é englobado por uma consciência externa que é o leitor. A cidade torna-se de fato múltipla, jamais a mesma, um caleidoscópio. Imagem compartilhada. Isso amplia a construção conceitual do elemento urbano: um caminho que se estende e que está em constante devir. Essa potência vindoura se apresenta na metáfora do horizonte.

Nesta experiência caleidoscópica que a leitura da cidade propõe, o cruzamento de experiências produz um sortimento de narrativas que se cruzam, se entrelaçam, se penetram e se reconstituem. Tudo isso é memória. Tudo isso é verificável em rastros. Nos rastros que pudemos tornar visíveis e que, no jogo, podem ainda ser adicionados em outras camadas, com outros itens e espelhamentos. E é sempre um sujeito que a instaura. É o olhar do sujeito que constrói o discurso de uma paisagem. Todas essas intenções para com o lugar são elementos observáveis nas narrativas que, quando mapeados, tornam-se evidências, rastros, marcas. Seus cruzamentos nos obrigam a focalizar e reconhecer que a cidade se mostra nos prismas de cada personagem.

Por isso a linguagem nos é extremamente relevante neste caso, pois ela é no corpo e por meio dela conhecemos a cidade. A linguagem só é uma interação quando expressa pelo e no corpo, sendo corpo um conjunto que funciona justamente por envolver faculdade simbólica e aparato físico. Expressão é gesto, é estar no mundo, experienciar o mundo, movendo-se nele, geograficamente, interagindo com o outro. 
A leitura pode sim ser uma ação coletiva, experiência compartilhada no espaço. É no movimento que a cidade se apresenta e, nesse jogo de referências, é representada. Nós somos corporeidades num tempo-espaço que chamamos mundo. Recriando este mundo, através da literatura e da leitura atribuímos sentidos únicos e ao mesmo tempo compartilhados, estamos em constante questionamento com relação a ser no mundo e é isso que nos propõe horizontes. Segundo Polesso (2017, p. 225):

Este é o devir. O estar geográfico, observar ainda na antemanhã, o alvorecer, iluminar as cartografias, explorá-las, compreender as representações de paisagem que a partir dessa interação do sujeito com o mundo surgem, para constantemente projetar horizontes.

A estrutura do horizonte na experiência do sensível se define no pensamento paisagem de Collot, no qual a percepção será sempre um ato de pensamento, perspectiva subjetiva, ponto de vista particular sobre o mundo.

O espaçamento designa a projeção do sujeito no espaço como condição de sua existência, um movimento no qual ele desiste da sua identidade fechada para se abrir para o mundo e para os outros. O espaço é uma dimensão essencial dessa abertura de identidade e estabelecimento de relações. Collot reforça que:

O espaçamento designaria então a sua [do sujeito] projeção no espaço como condição de sua existência. Contrariamente a toda uma tradição filosófica que vê nesse 'ser-no-mundo' [dasein] o risco de uma degradação, eu vejo também a chance que ele oferece ao sujeito de se realizar paradoxalmente assim que ele renuncia residir/habitar em si mesmo (COLLOT, 2011, p.34, tradução nossa). ${ }^{16}$

O espaço da linguagem, na prosa, especificamente em se tratando de paisagem, cria uma relação particular do sujeito com o real, pois manifesta sua presença no mundo. Através da linguagem é possível dar sentido ao mundo e ao seu lugar nele, ou seja, sua própria experiência de leitura do mundo. Essa experiência, que é também de construção da paisagem, como lugar do espaçamento do sujeito, traz um questionamento fundamental da fenomenologia: o pensamento não é apenas interior, pois não pode existir fora do mundo. É preciso estar no mundo, em contato com as coisas do mundo, para que o pensamento exista. E, se o pensamento torna o sujeito um ser no mundo, é porque ele ocorre de fato no espaçamento.

${ }^{16}$ No original: "L'espacement désignerait alors sa [du sujet] projection dans l'espace como la condition même de son existence. Contrairement à toute une tradition philosophique qui voit dans cet « être-jeté » le risque d'une déchéance, j'y vois aussi la chance qu'il offre au sujet de s'accomplir paradoxalement dès lors qu'il renonce à résider en lui-même". 
Merleau-Ponty (1964) trata a noção de sujeito, afirmando que je suis un champ, je suis une experiénce, e o descreve como uma situação espacial localizada (ou espacializada). O corpo é o lugar onde a práxis acontece. A consciência, para MerleauPonty, e o deslocamento no espaço são entendidos como a experiência do corpo e sua relação com o espaço. A percepção desse movimento, ou esse espaçamento nas relações, pressupõe um sujeito espacialmente situado, isto é, iniciado no mundo. No caso, a paisagem é o ponto de convergência dessas relações com o mundo, pois ela se dirige à imaginação. A paisagem é uma construção que ao mesmo tempo é origem, porque mundo, e horizonte, porque possibilidade.

O espaço literário traz à tona três elementos da experiência narrativa: o mundo, o sujeito e a linguagem, que podemos remeter aos elementos constitutivos da paisagem segundo Collot: site, regard e image (lugar, olhar e imagem). A narrativa propicia uma estrutura que permite uma relação com o mundo, a construção de um sujeito através dela e a construção do sujeito no mundo através da linguagem e da experiência.

Segundo Collot, a palavra horizonte, pela sua etimologia, está ligada a limite e pode se confundir com limite do campo visual. Porém, o horizonte está como um limite aberto, porque à medida que nos aproximamos, a linha vai se redesenhando. É um falso limite, uma potencialidade de busca infinita, contorno provisório que reorganiza a paisagem e nos convida a ampliar ou prolongar o que vemos pela via da imaginação. A estrutura do horizonte é um jogo de olhares que compõe a narrativa. É o que está dito, porque projeta, mas também o que está omitido, porque limita. É um jogo sutil entre o explícito e o implícito que constitui o horizonte e o faz transbordar do visível para o afetivo, para o desejo, para a experiência de leitura que se projeta para além do texto:

A linha do horizonte da paisagem é tão somente a manifestação exemplar de uma estrutura mais geral que Husserl nomeia estrutura do horizonte (Horizontstruktur), e que rege tanto a percepção das coisas no espaço quanto a consciência íntima do tempo e a relação com o outro. Esta estrutura me parece um jogo na arte da paisagem, tanto no oriente quanto no ocidente. Eu levanto a hipótese que isso se trata de uma estrutura antropológica universal, mesmo se cada civilização a interpreta e a exprime de maneira diferente. $O$ horizonte traça uma ligação entre as três instâncias que fundam, na maioria das culturas, a ordem do universo: a terra, o homem e o céu, que os chineses reúnem em uma tríade indissociável (Collot, 2011, p. 93-94, tradução nossa). ${ }^{17}$

${ }_{17}$ No original: "La ligne d'horizon du paysage n'est que la manifestation exemplaire d'une structure plus général que Husserl nomme structure d'horizon (Horizontstruktur), et qui régit aussi bien la perception des choses dans l'espace que la conscience intime du temps et le rapport à autrui. Cette structure me semble en jeu dans l'art du paysage, aussi bien en Orient qu'en Occident. Je fais l'hypothèse qu'il s'agit d'une structure anthropologique universelle, même si chaque civilisation l'interprète et l'exprime de façon différente. L'horizon trace un trait d'union entre les trois instances qui fondent, dans la plupart des cultures, l'ordre de l'univers : la terre, l'homme et le ciel, que les Chinois réunissent dans une triade indissociable". 
A estrutura do horizonte permite compreender os elementos narrativos que unem o visível e o invisível, o limite e o desejo/expectativa, o imaginário e o referencial/real, ela elucida/ilumina a relação fundamental do ser no mundo, porque o horizonte faz parte da estrutura da experiência. O horizonte se revela primeiramente através da percepção. Tanto a percepção quando a experiência são itens do campo da subjetividade, por isso é preciso ter cuidado e dar importância à construção narrativa das personagens e narradores, afinal, são eles que nos convidam a imaginar cidades.

A literatura é um exercício de alteridade e a perspectiva geográfica abre mesmo a possibilidade de estar no lugar do outro. Não num lugar metafórico apenas, como se estivéssemos vendo o mundo pelos olhos da personagem, mas como se fôssemos levados a construir um espaço ao nosso entorno a partir daquilo que é narrado. Os lugares vão adquirindo relevância, os itens da paisagem constroem a referencialidade ao nosso redor e, assim, projetamo-nos virtualmente nesses lugares. Lá estamos, como consciências englobantes, dando sentido ao espaço-tempo. Tornando o mundo, mundo.

Escrever sobre experiência leitora e urbana também é de certa maneira se colocar no lugar do outro, não apenas num lugar metafórico, mas ontologicamente, no lugar construído pelo outro, em sua perspectiva. É uma tentativa de interpretar e interpelar espaços caleidoscópicos constituídos por essas memórias que ora se somam, ora estão em conflito, estabelecendo um permanente exercício de alteridade.

O jogo aqui proposto colabora para a efetivação da presença do leitor na cidade e ainda o faz responsável por uma coleção de realemas, de itens da paisagem, adicionando camadas de importância e, possivelmente, algum tipo de afeto tanto na relação do leitor com a obra quanto com a cidade. O leitor-jogador aqui vislumbrado teria em mãos um repertório paisagístico e literário potencial.

Ocupar as cidades hoje, estar em contato com seus elementos constituintes, é um ato de resistência. O cerceamento do direito à rua, às manifestações, à ocupação de espaços, vem numa crescente interdição, é preciso fazer emergir mais registros, mais vozes, para termos mais horizontes de possibilidades.

Ocupar a cidade narrativa é também ocupá-la fisicamente, em sua materialidade, em seu conhecimento. Se a cidade é como nós a vemos, na literatura ela se torna a narrativa do nosso próprio desejo de ocupá-la. Ficamos sedentos pela emergência de novas histórias, novas personagens, vindas de lugares refeitos, repensados ou talvez nunca antes literários. Pensamos que a virtualidade e a literatura, que muito nos ajuda a compreender a geografia física e humana, associadas possam, de alguma maneira, continuar nos respondendo sobre a experiência de ser, de desejar ser, e de como ler novas cidades. 


\section{Referências}

Auerbach, Erich. Mimesis: a representação da realidade na literatura ocidental. São Paulo: Perspectiva, 2009.

Azurenha, Paulino; Lobo, Souza; Totta, Mário. Estrychnina. Porto Alegre: Artes e Ofícios, [1897], 1998.

Baкhtin, Mikhail. Esthétique et théorie du roman. Paris: Gallimard, 1978.

Barthes, Roland. L'effet de réel. Communications, 11, 1968. Recherches sémiologiques le vraisemblable. pp. 84-89. Disponível em: http://www.persee.fr/web/ revues/home/prescript/article/comm_0588-8018_1968_num_11_1_1158. Acesso em: 29/o6/2018. DOI 10.3406/comm.1968.1158.

Blanchot, Maurice. O espaço literário. Rio de Janeiro: Rocco, 2011.

Calvino, Italo. As cidades invisíveis. Rio de Janeiro: O Globo; São Paulo: Folha de São Paulo, 2003.

Collot, Michel. Le pensée-paysage. Paris: Actes Sud, 2011.

Collot, Michel. Pour une géographie littéraire. Paris: Éditions Corti, 2014.

Compagnon, Antoine. Le démon de la théorie: littérature et sense commun. Paris: Éditions du Seuil, 1998.

Even-Zohar, Itamar. Littérature. Les règles d'insertion des 'réalèmes' dans la narration. Porter Institut, 1985. p. 109-118. Disponível em: http://www.tau.ac. il/ itamarez/works/papers/translated/Even-Zohar_1985--Les\%2oregles\%2od' insertion\%2odes\%2o'realemes'\%2odans\%2ola\%2onarration.pdf. Acesso em: 29 jun. 2018.

Genette, Gerard. Figures III. Paris: Editions du Seuil, 1972.

Harvey, David. A revolução urbana. Belo Horizonte: UFMG, 1999

HaRvey, David. Cidades rebeldes: do direito à cidade à revolução urbana. São Paulo: Martins Fontes, 2014.

IsER, Wolfgang. L'acte de lecture - théorie de l'effet esthétique. Paris: Editions Mardaga, 1985 .

Jauss, Hans Robert. Pour une esthétique de la réception. Paris: Gallimard, 1978.

Jouve. A leitura. São Paulo: Editora UNESP, 2002.

Jouve, Vincent. Pour une analyse de l'effet-personnage. Littérature, n. 85, 1992. Forme, difforme, informe. pp. 103-111. Disponível em: http://www.persee.fr/web/ revues/home/prescript/article/litt_oo47-480o_1992_num_85_1_2607. Acesso em: 29 jun. 2018. DOI 10.3406/litt.1992.2607. 
Lefebvre, Henri. Espace et politique: Le droit à la ville II. 2 ed. Paris: Anthropos, 2000 .

Lefebvre, Henri. La production de l'espace. Paris: Anthropos, 1974.

LÉvy, Pierre. Qu'est-ce que le virtuel?. Paris: Université Paris VIII, 2007. Disponível em: http://hypermedia.univ-paris8.fr/pierre/virtuel/virto.htm. Acesso em: 29 jun. 2018.

Massey, Doreen B. Pelo espaço: uma nova política da espacialidade. Rio de Janeiro: Bertrand Brasil, 2008.

Merleau-Ponty, Maurice. Phénoménologie de la perception. Paris: Gallimard, 1945.

Merleau-Ponty, Maurice. Le visible et l'invisible. Paris: Gallimard 1964.

Moretri, Franco. A literatura vista de longe. Porto Alegre: Arquipélago, 2008.

Moretri Franco. Atlas do romance europeu. São Paulo: Boitempo, 2003.

Polesso, Natalia B. Literatura e cidade: cartografias metafóricas e memória insolúvel de Porto Alegre (1897-2013). 17 de janeiro de 2017. 234p. Tese de doutorado Pontifícia Universidade Católica do Rio Grande do Sul, Porto Alegre, 2017.

Ricoeur, Paul. La mémoire, l'histoire, l'oublie. Paris: Éditions du Seuil, 2000.

SAntos, Milton. Por uma geografia nova. São Paulo: Hucitec, 1996.

Todovov, Tzevan. Lo verosímil que no se podría evitar. In BARTHEs, Roland. Comunicaciones: Lo verosímil. Tiempo Contemporáneo: Buenos Aires, 1972. pp. 175178.

Westphal, Bertrand. La géocritique: réel, fiction, espace. Paris: Les Éditions de Minuit, 2007.

Recebido em o2 de julho de 2018.

Aprovado em 27 de fevereiro de 2019

\section{Resumo/Abstract/Resumen}

\section{O leitor no espaço: jogo e ocupação das cidades}

\section{Natalia Borges Polesso}

O presente artigo discute a ideia de um leitor espacializado. Para tanto, serão abordadas noções de leitura e de leitor em Jouve (2002), Genette (1972), Jauss (1978) e Iser (1985), bem como as noções de efeito de real, em Barthes (1968) e efeito personagem, em Jouve (1992). O espaço será debatido via geografia literária e geocrítica, especificamente nas teorias de Collot (2011, 2014) e Westphal (2007). Moretti 
(2003, 2008) também tem um papel fundamental na construção da ideia de leitura. Além disso, há uma discussão sobre o verossímil, em Todorov (1972), Compagnon (1998) e Ricoeur (2000). Para abordar a ideia de experiência leitora espacial nos baseamos em uma abordagem fenomenológica do sujeito leitor através de MerleauPonty (1964). Há também uma proposta de jogo literário, implicando o leitor no espaço, desenvolvida em Polesso (2017).

Palavras-chave: leitura, experiência, espaço, jogo.

\section{The Reader in Space: Play and Occupation of the Cities}

\section{Natalia Borges Polesso}

This article discusses the concept of a spatialized reader. To do this, the notions of reading and reader in Jouve (2002), Genette (1972), Jauss (1978) and Iser (1985) will be addressed, as well as the notions of "the effect of reality" in Barthes (1968), and those of "character effect" in Jouve (1992). The notion of space will be analysed through literary geography and geocriticism, based on the theories of Collot (2011, 2014) and Westphal (2007). Moretti $(2003,2008)$ also plays a key role in the construction of the idea of reading. There is also a discussion on verisimilitude in Todorov (1972), Compagnon (1998) and Ricoeur (2000). To approach the concept of the spatial reader's experience, we apply a phenomenological approach to the theme of the reader based on Merleau-Ponty (1964). The article also proposes a literary game that involves the reader in space, developed by Polesso (2017).

Keywords: reading, experience, space, play/game.

\section{El lector en el espacio: juego y ocupación de las ciudades}

\section{Natalia Borges Polesso}

Este artículo discute la idea de un lector espacializado. Para ello serán abordadas las nociones de lectura y de lector en Jouve (2002), Genette (1972), Jauss (1978) e Iser (1985), así como las nociones de "efecto de lo real", en Barthes (1968), y las de "efecto personaje" en Jouve (1992). El espacio se tratará a través de la geografía literaria y la geocrítica, a partir de las teorías de Collot (2011, 2014) y Westphal (2007). Moretti (2003, 2008) también juega un papel clave en la construcción de la idea de lectura. Existe además una discusión sobre la verosimilitud en Todorov (1972), Compagnon (1998) y Ricoeur (2000). Para abordar la idea de la experiencia del lector espacial, nos basamos en un enfoque fenomenológico del tema del lector a través de Merleau-Ponty (1964). También se propone un juego literario que involucra al lector en el espacio, desarrollado en Polesso (2017).

Palabras clave: lectura, experiencia, espacio, juego. 